\title{
ANALYSIS AND DETECTION OF WILDFIRES BY USING PRISMA HYPERSPECTRAL IMAGERY
}

\author{
D. Spiller ${ }^{1,3, *}$, L. Ansalone ${ }^{1}$, S. Amici ${ }^{2}$, A. Piscini ${ }^{2}$, P.P. Mathieu ${ }^{3}$ \\ ${ }^{1}$ Italian Space Agency, Rome, Italy - luigi.ansalone@ asi.it \\ ${ }^{2}$ Istituto Nazionale di Geofisica e Vulcanologia (INGV), Sezione ONT, 00143 Rome, Italy \\ (stefania.amici, alessandro.piscini)@ingv.it \\ ${ }^{3} \Phi$-Lab, EOP, European Space Agency, ESRIN, Frascati, Rome, Italy \\ (dario.spiller,pierre.philippe.mathieu)@esa.int
}

Commission III, WG III/4

KEY WORDS: PRISMA, hyperspectral imagery, fire detection, multiclass classification, convolutional neural network.

\begin{abstract}
:
This paper deals with the analysis and detection of wildfires by using PRISMA imagery. Precursore IperSpettrale della Missione Applicativa (Hyperspectral Precursor of the Application Mission, PRISMA) is a new hyperspectral mission by ASI (Agenzia Spaziale Italiana, Italian Space Agency) launched in 2019. This mission provides hyperspectral images with a spectral range of 0.4-2.5 $\mu \mathrm{m}$ and an average spectral resolution less than $10 \mathrm{~nm}$. In this work, we used the PRISMA hypercube acquired during the Australian bushfires of December 2019 in New South Wales. The analysis of the image is presented considering the unique amount of information contained in the continuous spectral signature of the hypercube. The Carbon dioxide Continuum-Interpolated Band Ratio $\left(\mathrm{CO}_{2} \mathrm{CIBR}\right.$ ), Hyperspectral Fire Detection Index (HFDI), and Normalized Burn Index (NBR) will be used to analyze the informative content of the image, along with the analysis of some specific visible, near-infrared and shortwave-infrared bands. A multiclass classification is presented by using a 1-dimensional convolutional neural network (CNN), and the results will be compared with the ones given by a support vector machine classifier reported in literature. Finally, some preliminary results related to wildfire temperature estimation are presented.
\end{abstract}

\section{INTRODUCTION}

Detection and accurate monitoring of risk areas is becoming increasingly important to counteract severe and destructive wildfires. As reported in the survey paper (Barmpoutis et al., 2020), satellite-based optical remote sensing (RS) represents a costeffective way to detect, map, and investigate wildfires. For instance, in (Domenikiotis et al., 2002, Domenikiotis et al., 2003) the assessment of the burned areas was investigated by using the National Oceanic and Atmospheric Administration/Advanced Very High Resolution Radiometer (NOAA/AVHRR) and Landsat TM. NASA is providing near real-time global fire monitoring using data from MODIS and VIIRS (Davies et al., 2020).

Among the different remote sensing technologies, hyperspectral (HS) imagery presents nonpareil features in support to fire detection (Veraverbeke et al., 2018). Indeed, HS space-born imagery provide the required information in the infrared wavelengths to detect active fires and burnt areas, as discussed in (Barducci et al., 2002, Barducci et al., 2004, Hua and Shao, 2017). Previous results based on EO-1 Hyperion have shown the HS potentialities for RS applications (Waigl et al., 2019) for fire detection and temperature retrieval over selected Alaskan boreal forest fires. The problem of temperature estimation by using HS data has been covered also in other works, such as (Dennison et al., 2006, Barducci et al., 2004, Dennison and Matheson, 2011, Matheson and Dennison, 2012). In (Amici et al., 2011), a multi-resolution spectral analysis of wildfire focused on the potassium emission signatures has been performed by using laboratory, airborne and spaceborne hyperspectral remote sensing. The potassium emission signature

\footnotetext{
* Corresponding author
}

has been used also in (Vodacek et al., 2002) for the detection of burning biomass. In (Griffin et al., 2000), a characterization and delineation of plumes, clouds and fires in hyperspectral images has been discussed.

In this paper, HS images from the Italian satellite PRISMA (PRecursore IperSpettrale della Missione Applicativa) will be used. Many details on the PRISMA mission starting from the initial design to the operative life can be found in literature (Galeazzi et al., 2008, Ananasso et al., 2009, Lopinto et al., 2012, Colini et al., 2013, Colini et al., 2014, Candela et al., 2016, Loizzo et al., 2016, Guarini et al., 2018, Loizzo et al., 2018, Loizzo et al., 2019, Coppo et al., 2019, Coppo et al., 2020). PRISMA represents the first mission with a dedicated HS camera of the recent years, and other similar mission are planned in the future years (Carmona et al., 2017, CawseNicholson et al., 2021, Guanter et al., 2015, Nieke and Rast, 2018). The PRISMA satellite, launched on 22 March 2019, holds a hyperspectral and panchromatic payload which is able to acquire images with a worldwide coverage. The HS camera works in the spectral range of $0.4-2.5 \mu \mathrm{m}$, with 66 and 173 channels in the VNIR (Visible and Near InfraRed) and SWIR (Short-Wave InfraRed) regions, respectively. The average spectral resolution is less than $10 \mathrm{~nm}$ on the entire range with an accuracy of $\pm 0.1 \mathrm{~nm}$, while the ground sampling distance of PRISMA images is about $5 \mathrm{~m}$ and $30 \mathrm{~m}$ for panchromatic and hyperspectral camera, respectively.

The area of interest of this work is located in Australia, where an high number of wildfires has been registered in these late years. Indeed, the impact of climate change on the risk of forest and grassland fires in Australia has been subject to studies, e.g. 
(Pitman et al., 2007, Deb et al., 2020), having important effects both on the local communities (Weber et al., 2019) and the environment (Kumar et al., 2021).

The continuous spectral signature of PRISMA along with neural network analysis can open new unexplored research opportunities (Piscini and Amici, 2015, Amici and Piscini, 2021). The main contributions of this work to the state of the art are the following:

1. Discussing the advantages of using PRISMA HS data over using multi-spectral data by analysing the informative content of VNIR and SWIR channels and hyperspectral indices such as the Carbon dioxide Continuum-Interpolated Band Ratio ( $\left.\mathrm{CO}_{2} \mathrm{CIBR}\right)$, the Hyperspectral Fire Detection Index (HFDI), and the Normalized Burn Index (NBR).

2. Presenting the potentialities of deep learning methodologies based on 1D convolutional neural networks to catch spectral dependencies. The results will be compared with the ones obtained in (Amici and Piscini, 2021) where a support vector machine (SVM) classifier was used.

3. Evaluating preliminary results for the wildfire temperature estimation using a linear mixture model analysis

4. Discussing the possibility and benefit to integrate HS based approach in future monitoring systems in case of wildfire alerts and disasters.

The rest of the paper is organized as follows. Sec. 2 deals with the description of the area of interest and the hyperspectral datacube. In Sec. 3 the classification and temperature estimation approaches are explained, while in Sec. 4 the results of the proposed analyses are reported. A critical discussion of the output of this study is reported in Sec. 5 and conclusions are given in Sec. 6.

\section{STUDY AREA DESCRIPTION AND ANALYSIS}

\subsection{Area of interest}

The study area of this paper has been chosen in Australia specifically in New South Wales about $250 \mathrm{~km}$ north of Sydney in the Ben Halls Gap National Park (BHGNP) which covers 2500 ha, and is situated $60 \mathrm{~km}$ south-east of Tamworth and $10 \mathrm{~km}$ from the township of Nundle. The park is located at a comparatively high altitude that results in generally cool temperatures and high rainfall. However, in late 2019, the simultaneous occurrence of high temperatures and wind speeds, and low relative humidity, produced the conditions for the development of a high-intensity wildfire behavior. The RGB composite of the study area is reported in Fig. 1. As can be seen, two active wildfires can be identified, a southern one around $151.2^{\circ} \mathrm{E}$, $31.59^{\circ} \mathrm{S}$, and a northern one around $151.3{ }^{\circ} \mathrm{E}, 31.46^{\circ} \mathrm{S}$. The PRISMA image over this area of interest has been acquired on December 27, 2019.

\subsection{Analysis of the hyperspectral datacube}

The PRISMA data are made available for free for research purposes by the Italian Space Agency (ASI) (Guarini et al., 2018). Hyperspectral and panchromatic data at $30 \mathrm{~m}$ and $5 \mathrm{~m}$ resolution, respectively, are delivered in HDF5 format with four options:

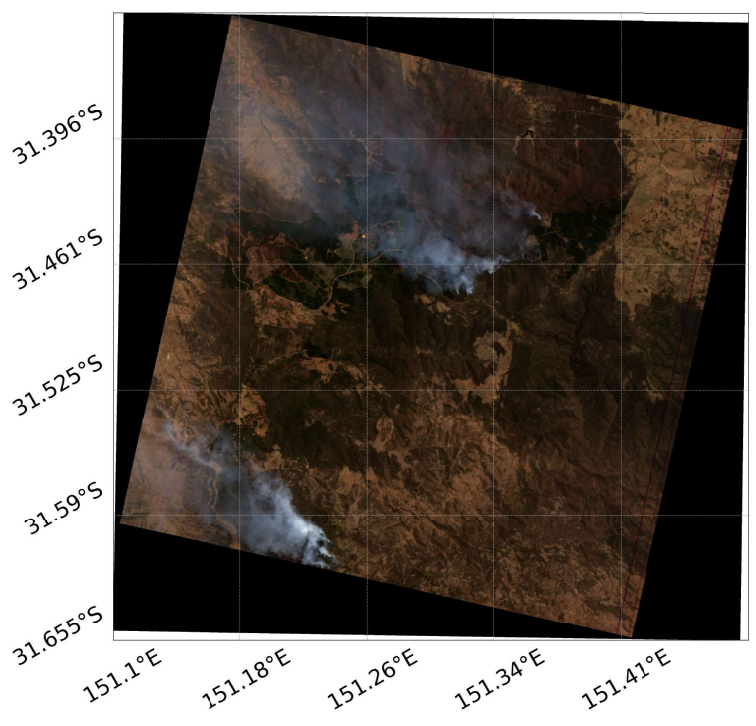

Figure 1. RGB composite of the ROI in Australia.

1. Level 1 , radiometrically corrected and calibrated TOA (top of atmosphere) data;

2. Level 2B, geolocated at-ground spectral radiance product;

3. Level 2C, geolocated at-surface reflectance product; and

4. Level 2D, geocoded version of the Level $2 \mathrm{C}$ product.

In this work, we used both Level 2B and Level 2D. Combining the spectral bands of PRISMA, several spectral indices can be evaluated to inspect and analyse the informative content of the chosen scene. Here, we discuss the Hyperspectral Fire Detection Index (HFDI), the Carbon Dioxide ContinuumInterpolated Band Ratio $\left(\mathrm{CO}_{2}\right.$ - $\left.\mathrm{CIBR}\right)$, the Normalized Burn Ratio (NBR), and other information retrieved by VNIR and SWIR bands. A much more detailed analysis of these spectral indices applied to the same PRISMA scene are reported in (Amici and Piscini, 2021).

2.2.1 False color composite The false color composite is reported in Fig. 2. This image is obtained with an RGB triplet given by the bands at $1700 \mathrm{~nm}, 1100 \mathrm{~nm}$, and $660 \mathrm{~nm}$, respectively. Fire smoke is not captured in these wavelength, thus allowing an inspection of the terrain where one can recognize active fire pixels as the ones shown in red, whereas the burnt area appears as dark green pixels and fresh vegetation as light green pixels.

2.2.2 HFDI The authors of (Dennison and Matheson, 2011, Waigl et al., 2019) suggest that a very accurate fire detection analysis can be carried out by using the hyperspectral fire detection index (HFDI), a normalized difference index defined as

$$
\mathrm{HFDI}=\frac{L_{2430 \mathrm{~nm}}-L_{2060 \mathrm{~nm}}}{L_{2430 \mathrm{~nm}}+L_{2060 \mathrm{~nm}}}
$$

where $L_{2430 \mathrm{~nm}}$ and $L_{2060 \mathrm{~nm}}$ are the spectral radiances at two SWIR bands around $2430 \mathrm{~nm}$ and $2060 \mathrm{~nm}$, respectively.

The HFDI index is reported in Fig. 3 and one can appreciate the different intensity of pixels belonging to active fire with respect to neighbouring pixels. 


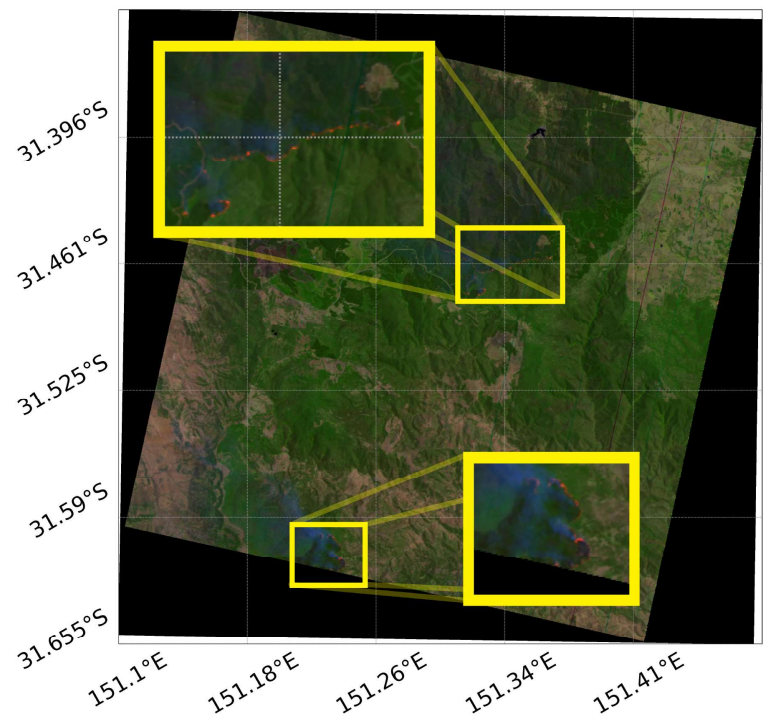

Figure 2. False color image for visual inspection of active fires.

2.2.3 $\mathrm{CO}_{2}$-CIBR The Carbon Dioxide ContinuumInterpolated Band Ratio ( $\mathrm{CO}_{2}$-CIBR) (Dennison et al., 2006) can be used to separate the dominantly emitted radiance from the dominantly reflected radiance and is described by

$$
\mathrm{CO}_{2}-\mathrm{CIBR}=\frac{L_{2010 \mathrm{~nm}}}{0.666 L_{1990} \mathrm{~nm}+0.334 L_{2040} \mathrm{~nm}} .
$$

The $\mathrm{CO}_{2}$-CIBR index is shown in Fig. 4 considering the interval $[0.6,1.8]$ for a better visualization.

2.2.4 NBR The Normalized Burn Ration (NBR) index combines atmospherically-corrected bands at $1088 \mathrm{~nm}$ and $2020 \mathrm{~nm}$ in a normalized difference ratio, i.e.

$$
\mathrm{NBR}=\frac{L_{1088} \mathrm{~nm}-L_{2020 \mathrm{~nm}}}{L_{1088} \mathrm{~nm}+L_{2020 \mathrm{~nm}}}
$$

The NBR index is shown in Fig. 5. Also in this case, active fire pixels are easily distinguished from the other pixels.

Burn severity can also be estimated using the differenced Normalized Burn Ratio or dNBR, which is used by land managers in the USA to assess landscape-level burn severity (Key and Benson, 2006). The dNBR is computed from pre-fire NBR minus post-fire NBR. However, only the NBR index is used for the purposes of this study.

2.2.5 Active fire pixels detection in the far SWIR domain The Level 2D band at $2490 \mathrm{~nm}$ is reported in Fig. 6. As can be seen, saturated pixels with reflectance equal to 1 are associated to the active fire pixels already detected with the previous analyses. With the proper threshold, the active fire pixel map can be obtained as it is reported in Fig. 7.

2.2.6 Smoke detection in the VNIR domain Smoke can be quite easily detected by looking at the VNIR bands. For instance, the $411 \mathrm{~nm}$ band is reported in Fig. 8. One can appreciate how the smoke pixels are separated from the neighbouring pixels. Similarly to the previous SWIR case, also here a smoke map can be developed by using the proper threshold.

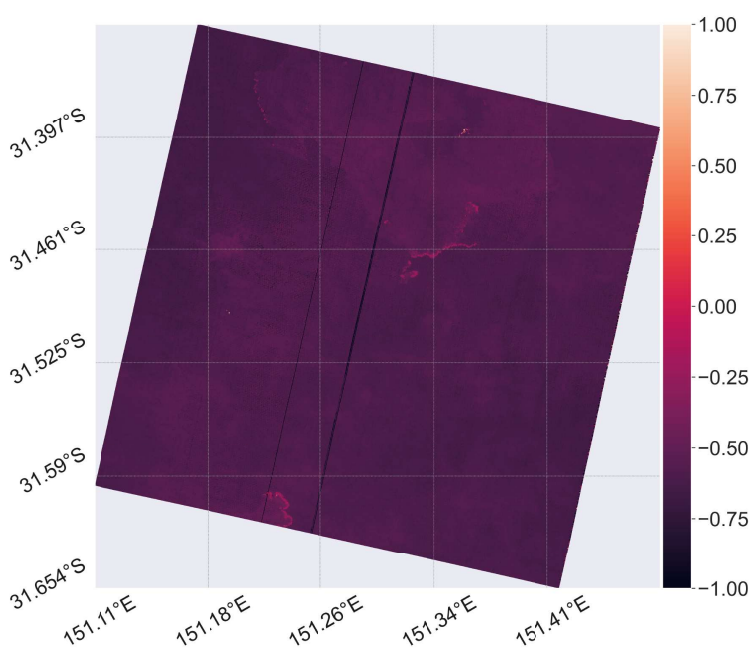

Figure 3. HFDI index.

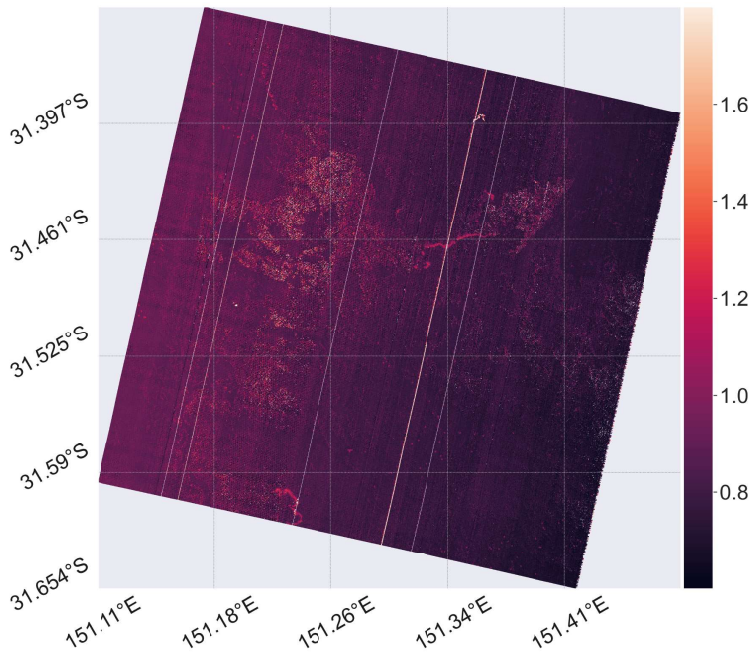

Figure 4. $\mathrm{CO}_{2}$-CIBR index with pixels in the interval $[0.6,1.8]$

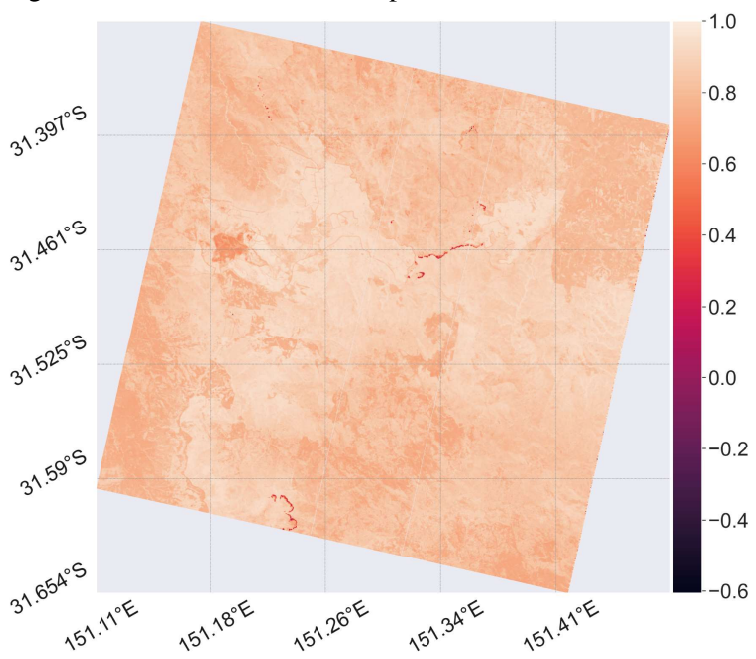

Figure 5. NBR index. 


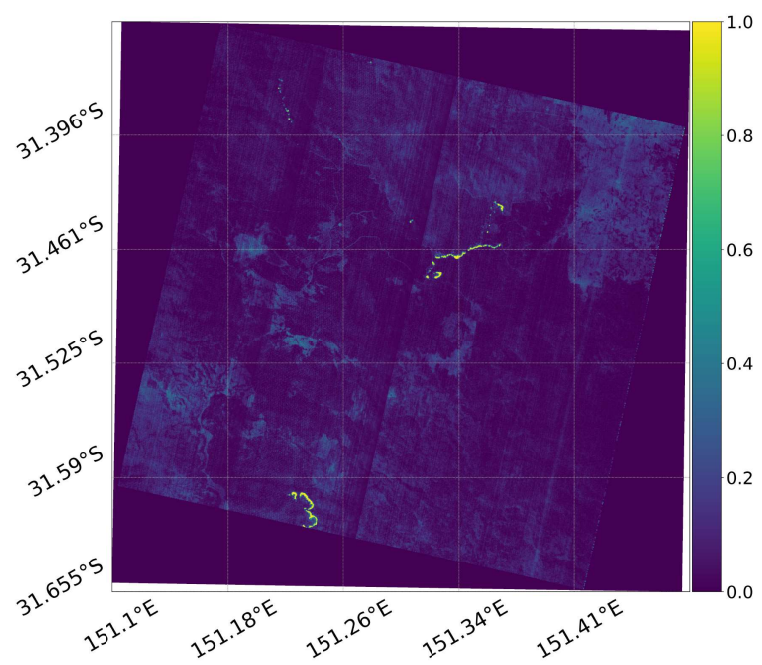

Figure 6. Level 2D SWIR band at $2490 \mathrm{~nm}$.

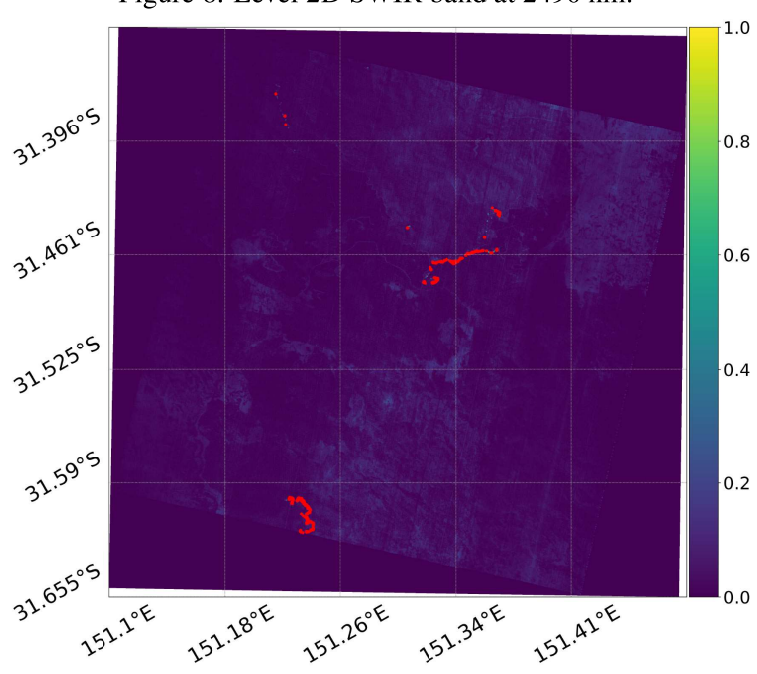

Figure 7. Level 2D SWIR band at $2490 \mathrm{~nm}$ with saturated pixels highlighted in red.

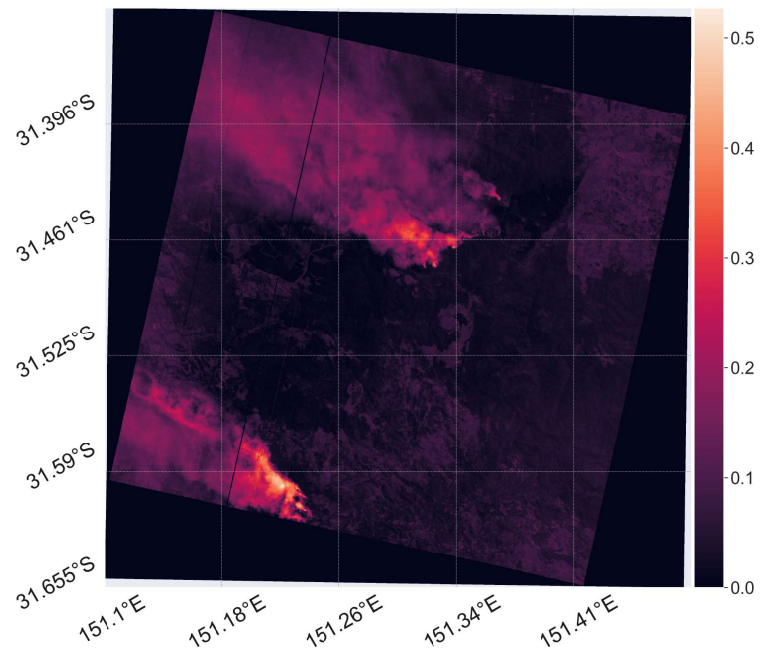

Figure 8. Level 2D SWIR band at $411 \mathrm{~nm}$.

\section{METHODS AND ANALYSIS}

\subsection{Manual classification based on spectral analysis}

For the implementation of the automatic segmentation based on an artificial intelligence approach, the labelling of some reference pixels for the training and validation operations is needed. To this aim, the reference pixels already determined in (Amici and Piscini, 2021) have been used. For the sake of clarity, we report here a summary of the manual classification procedure that has been exploited to determine the reference pixels. Exploring the false color composite in Fig. 2 and looking at the PRISMA spectral profile, which was comparable with the corresponding classes that can be found in the literature (Waigl et al., 2019), the following number of labelled pixels has been selected from the southern wildfire:

- 48 pixels for active fires (class 0 ),

- 48 pixels representing smoke (class 1),

- 12 pixels for freshly burned areas (class 2),

- 36 pixels for vegetation (high vegetation, bushes and low vegetation, class 3 ), and

- 48 pixels for the bare soil class (bare soil/road/anthropic, class 4$)$.

The training set represents $83 \%$ of the labelled data, while the remaining $17 \%$ was selected for the classification validation. It is noteworthy that the amount of labelled data is quite small and can only be used to run a simple CNN model for a preliminary validation of the classification approach.

\subsection{Automatic classification with a 1D CNN}

The classification model used in this work is inspired by the one described in (Hu et al., 2015) and is represented in Fig. 9. The input is the pixel spectrum comprising the SWIR and the VNIR channels for the PRISMA data. Thus, it is an array with $C=234$ elements (after removal of some useless original data in the input hyper-cube). The first hidden layer is a onedimensional (1D) convolutional layer with kernel equal to 3, $n_{1}=112$ filters, same padding, relu activation function, and $l 2$ kernel regularizer. After the convolutional layer, there is a max pooling layer with pool size of 2 and stride of 2 (with respect to Fig. 9, note that $n_{2}=n_{1}$ ). The result of this max pooling is

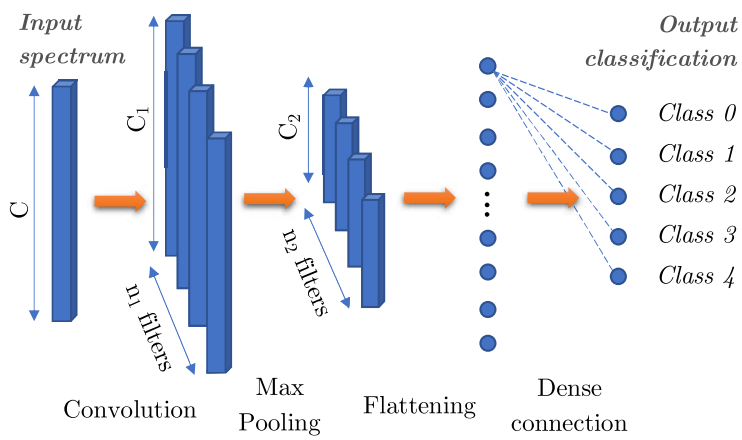

Figure 9. Architecture of the CNN model for the multi-class classification. 
then passed into a flattening layer, and connected to a fully connected layer of 128 units with $R e L U$ activation. The last layer is a dense unit for the multi-class classification with softmax activation function. Note that the values of $C_{1}$ and $C_{2}$ in Fig. 9 depend on the architecture of the network and can be easily evaluated. The model is trained using the Adam optimizer and the categorical crossentropy loss function. The whole network has been implemented using Python and Keras.

\subsection{Temperature estimation}

Temperature estimation can be attained by using the PRISMA level 2B images (bottom of atmosphere - BOA - radiance) and a linear mixture model, according to approach shown in (Waigl et al., 2019). The pixel signal can be approximated by the linear mixture signal $L_{\lambda, L M}$ that is expressed as a weighted average of $n$ sources $L_{\lambda}\left(T_{i}\right)$ (modeled as Planck black bodies) and $m$ background signals $L_{j, b k g}$ (chosen as other pixels in the same image), i.e.

$$
L_{\lambda, L M}=\sum_{i=1}^{n} p_{i, f i r e} L_{\lambda}\left(T_{i}\right)+\sum_{j=1}^{m} p_{i, b k g} L_{j, b k g},
$$

where the weight parameters $p_{i}$ and $p_{j}$ are defined such that $\sum_{i=1}^{n} p_{i, f i r e}+\sum_{j=1}^{m} p_{i, b k g}=1$. A least square method is used to estimate the parameters $p_{i}, p_{j}$ and the temperatures $T_{i}$.

However, differently from (Waigl et al., 2019) where they use at-sensor radiance, here we have used bottom-of-atmosphere radiance in order to make it easier and more consistent to approximate the hot sources with Planck black bodies. Moreover, the background signal is chosen directly from the image, selecting some non-fire pixels from the other for classes previously defined.

\section{RESULTS}

\subsection{Classification results}

The results of the training over the southern wildfire are summarized in Table 1. The final overall accuracy of the model on the validation dataset is $97.83 \%$, which is slightly higher than 96.87\% reported in (Amici and Piscini, 2021) where a SVM was used.

\begin{tabular}{lcccc}
\hline & Precision & Recall & F1-Score & Support \\
\hline 0 - Fire & 1.00 & 1.00 & 1.00 & 10 \\
1 - Smoke & 1.00 & 1.00 & 1.00 & 9 \\
2 - Burned & 1.00 & 1.00 & 1.00 & 3 \\
3 - Vegetation & 0.92 & 1.00 & 0.96 & 12 \\
4 - Bare soil & 1.00 & 0.92 & 0.96 & 12 \\
\hline accuracy & & & 0.98 & 46 \\
macro avg & 0.98 & 0.98 & 0.98 & 46 \\
weighted avg & 0.98 & 0.98 & 0.98 & 46 \\
\hline
\end{tabular}

Table 1. Accuracy measures for the validation dataset.

The segmentation map for the southern wildfire is reported in Fig. 10, and it can be compared with the one produced by the SVM in (Amici and Piscini, 2021) and shown in Fig. 11. As can be seen, the results are pretty similar apart from the western part, where the SVM map returned a burned area which is not captured by the 1D CNN model. Finally, the segmentation map for the northern wildfire is reported in Fig. 12. The legend with the colors of the five classes has been reported only once in Fig. 12 .

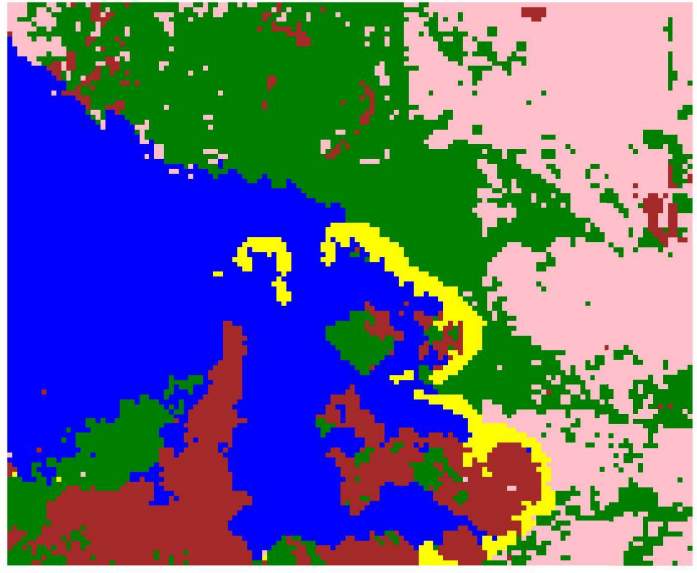

Figure 10. Results of the classification prediction from the proposed CNN model, southern wildfire.

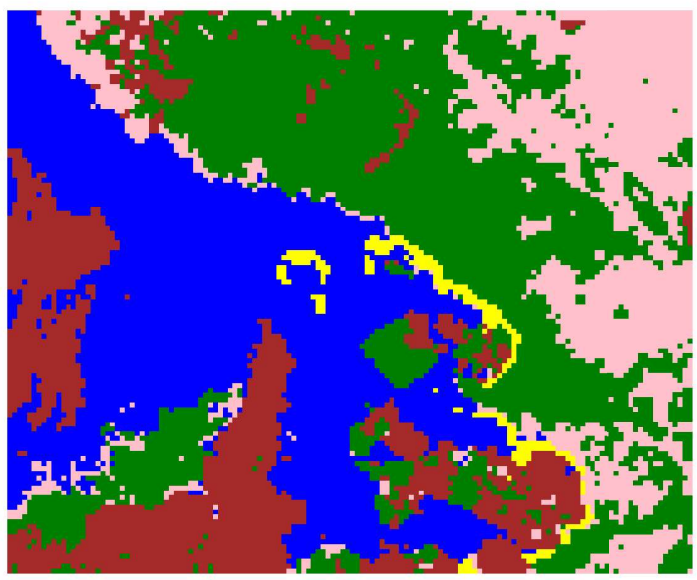

Figure 11. Results of the classification prediction from the SVM of (Amici and Piscini, 2021), southern wildfire.

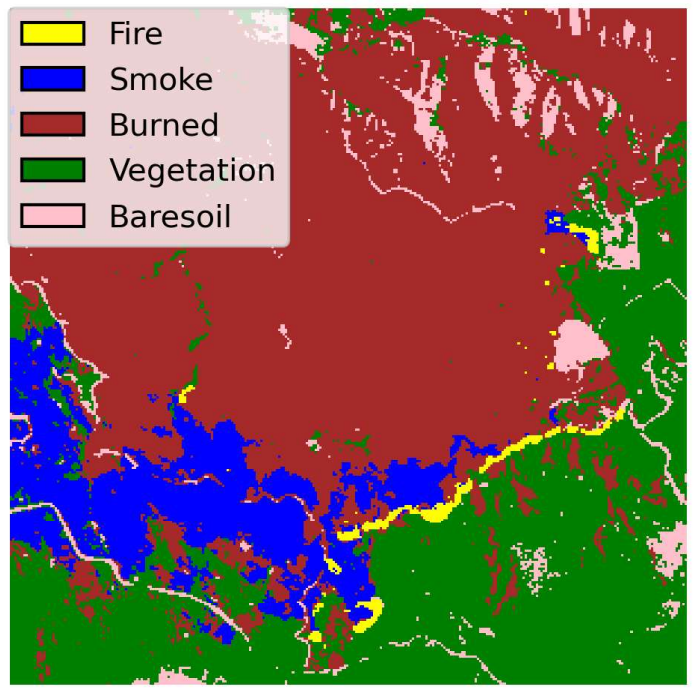

Figure 12. Results of the classification prediction from the proposed CNN model, northern fire. 


\subsection{Temperature estimation results}

For this numerical example, the southern wildfire has been chosen to select the pixel to be analysed. One issue to be considered when dealing with the approach described in Sec. 3.3 is that the wavelength interval between $1900 \mathrm{~nm}$ and 2450 $\mathrm{nm}$ is often affected by saturation when observing hot pixels. Hence, we are not recording the entire signal, but only the one that the sensor is able to record. This problem can be seen in Fig. 13, where the behaviour of the fire curve is anomalous after $1900 \mathrm{~nm}$ (the active fire pixel related to the fire spectral curve is reported in the small plot in the bottom left of the figure). Indeed, the fire curve is higher than the not-fire one in the SWIR region, but after $1900 \mathrm{~nm}$ is decreasing instead of increasing, as one should expect comparing with the Planck curves reported for $600 \mathrm{~K}, 700 \mathrm{~K}$, and $800 \mathrm{~K}$ (scaled by a factor 10 for visualization purposes). The saturation problems clearly appears when looking at the reflectance product, level 2D, which is reported in Fig. 14, where the saturation level equal to 1 is attained after $2000 \mathrm{~nm}$. Accordingly, the fitting with the Planck black body curve could be completely meaningless in this region.

As a result of the saturation issue, when we try to fit the entire SWIR region between $1400 \mathrm{~nm}$ and $2450 \mathrm{~nm}$ the results are not satisfactory. Indeed, the least-square technique returns a solution that fits the input curve, as shown in 15 . The blue

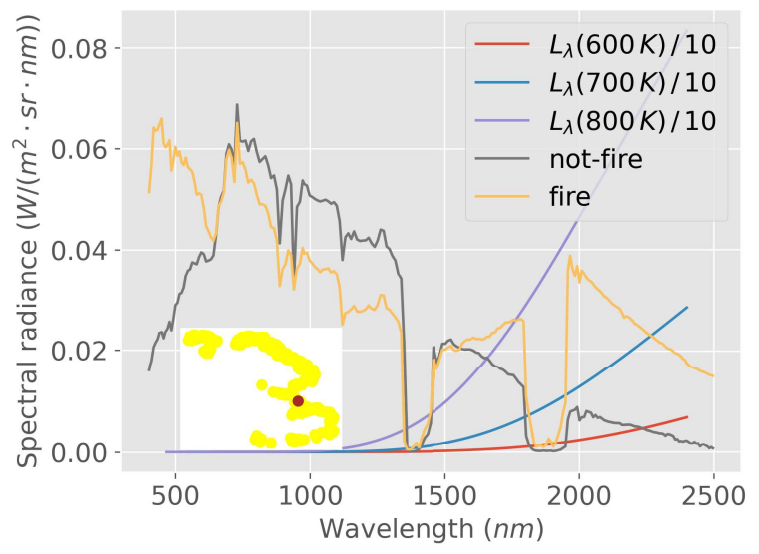

Figure 13. Comparison between spectra of fire and non-fire pixels.

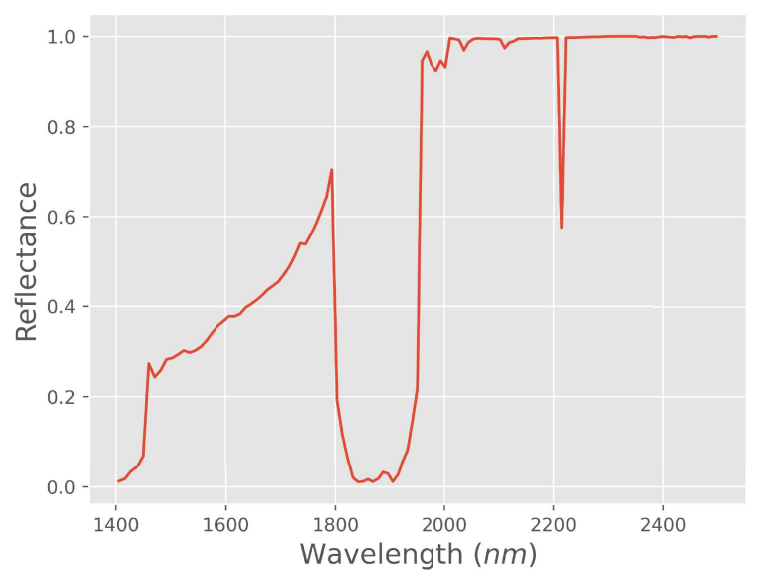

Figure 14. Reflectance of the reference fire pixel. line represents the spectral signal of the active fire pixel, while the red line represents the linear mixture model. Two fitting temperatures have been used, where the first one only fits the interval $1440 \mathrm{~nm}-1800 \mathrm{~nm}$, while the second one only fits the interval $1900 \mathrm{~nm}-2450 \mathrm{~nm}$. The result of this approach is the following:

- In the interval $1440 \mathrm{~nm}-1800 \mathrm{~nm}$, a fitting temperature of $645.4 \mathrm{~K}$ has been found, with $p_{1, \text { fire }}=39.4 \%$.

- In the interval $1900 \mathrm{~nm}-2450 \mathrm{~nm}$, a fitting temperature of $1928.9 \mathrm{~K}$ has been found, with $p_{2, \text { fire }}=0.02 \%$.

The interpretation of these results is that the most relevant and meaningful fitting temperature is the first one equal to 645.4 $\mathrm{K}$. The second temperature is too high for a wildfire, and this wrong estimation is due to the saturation of the sensor and the wrong spectral curve registered in the far SWIR domain. However, this fitting approach is affected by the wrong spectral profile after $1900 \mathrm{~nm}$ so that also the first temperature is not fully reliable.

A better approach would be to focus only in the wavelength interval between $1440 \mathrm{~nm}-1800 \mathrm{~nm}$. In this case, only one temperature is used for the fitting procedure. The results are shown in Fig. 16, and the fitting temperature is $717.8 \mathrm{~K}$ with

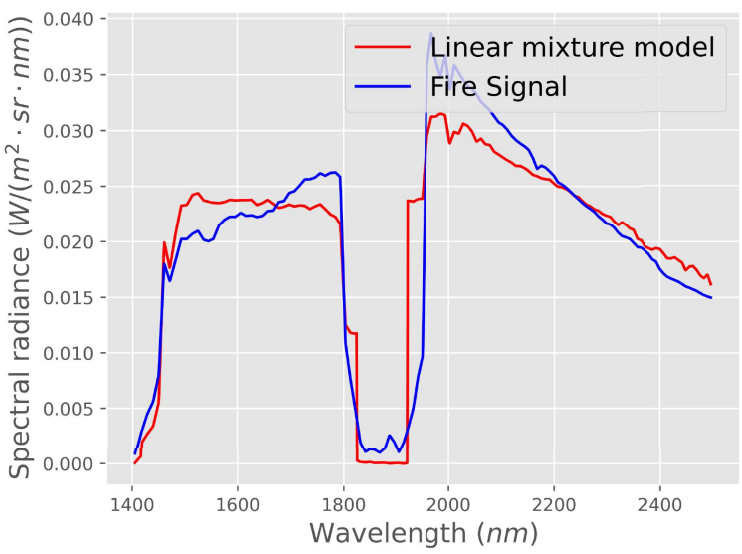

Figure 15. Results of linear mixture analysis for temperature retrieval in the entire SWIR interval.

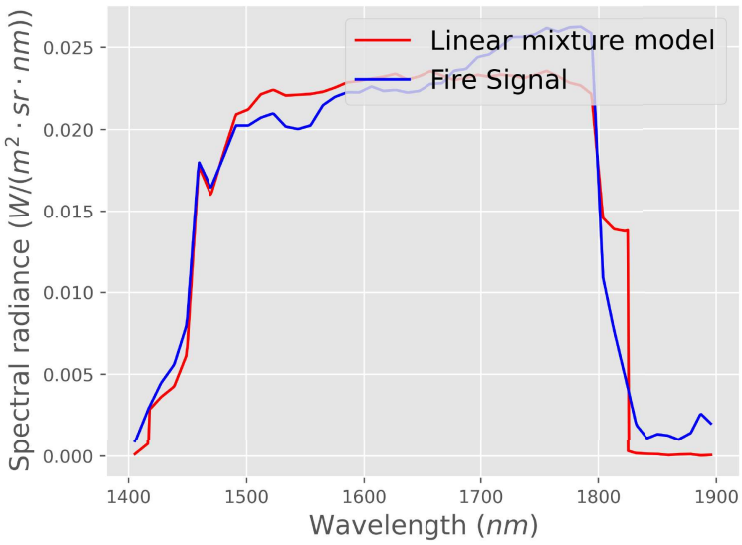

Figure 16. Results of linear mixture analysis for temperature retrieval in the SWIR interval $1440 \mathrm{~nm}-1800 \mathrm{~nm}$. 
$p_{1, \text { fire }}=13.5 \%$. As can be seen, the previous estimate has been slightly changed, but this result is more reliable as no saturation is detected in the input curve for the new wavelength interval.

\section{DISCUSSION}

The results of this paper demonstrate the potentialities of PRISMA hyperspectral data with regard to wildfire analysis and detection. The availability of a continuous and reliable spectral signatures allows to analyse the image information obtaining quite confident interpretations of the observed areas. As a result, reference pixels can be identified and used to train machine learning models. Even though the number of training and validation pixels must be increased to thoroughly discuss the generalization ability of the proposed 1D CNN model, the prediction map attained for the northern wildfire looks quite reliable and classes are well defined and distinguished. Checking the results in Fig. 12 with all the figures from Fig. 1 to Fig. 8, one can appreciate that the classes are quite close to what a visual inspection can provide. Future works will focus on the possibility to exploit more PRISMA images with wildfire in order to provide a more robust insight into the classification task

The training and validation datasets are not big enough to perform a reliable comparative analysis between our predictive model and the SVM one reported in (Amici and Piscini, 2021). According to our understanding and experience, this result is an indication that PRISMA spectral signatures allow to distinguish quite easily the different classes and the 1D CNN model is able to effectively learn from these information.

The possibility to use the far SWIR bands around $2400 \mathrm{~nm}$ to detect candidate areas of active fire is one of the bigger advantages when talking about wildfire early-warning. Even though such an operative scenario goes beyond the possibilities of PRISMA, this is something that can be considered for future missions dedicated to environmental analysis and natural hazards, risks and disasters management. Future missions embarking hyperspectral cameras could focus on detecting hotspots and candidate active fires, also providing on-board estimation of the pixel temperature with the approach described in Sec. 3.3. Indeed, all these analyses do not require high computational power, and could be easily deployed on-board future spacecrafts.

Finally, it is worthy to say that, even though the temperature estimation proposed in this work is preliminary and needs further analysis, the register temperature of $666.4 \mathrm{~K}$ is consistent with the range of temperatures reported in other works (Kaufman et al., 1998, Dennison et al., 2006), as active wildfires usually present peak temperatures at around $1000 \mathrm{~K}$ for flaming and around $600 \mathrm{~K}$ for the smoldering phase.

\section{CONCLUSION}

This paper has shown some analyses concerning a wildfire occurred in Australia in December 2019 and recorded by the hyperspectral remote sensing satellite PRISMA. The results of this paper demonstrate that the hyperspectral datacube provided by PRISMA allows one to perform many different and complementary analyses to study different aspects of the wildfire. A preliminary descriptive analysis of the area of interest has been carried out by looking at different spectral bands and spectral indices. Then, an automatic classification based on a onedimensional convolutional neural network has been performed. Finally, the temperature of the wildfire has been estimated by using a least-square fitting technique and a reference black body spectral profile. These preliminary analyses set the basis for future investigations that can be extended to other images and compared with other sensors.

\section{REFERENCES}

Amici, S., Piscini, A., 2021. Exploring PRISMA Scene for Fire Detection: Case Study of 2019 Bushfires in Ben Halls Gap National Park, NSW, Australia. Remote Sensing, 13(8). http://doi.org/10.3390/rs13081410.

Amici, S., Wooster, M. J., Piscini, A., 2011. Multiresolution spectral analysis of wildfire potassium emission signatures using laboratory, airborne and spaceborne remote sensing. Remote Sensing of Environment. http://doi.org/10.1016/j.rse.2011.02.022.

Ananasso, C., Bianco, G., Candela, L., Dini, L., Garramone, L., Loizzo, R., Nirchio, F., Serra, M., 2009. Italian Space Agency pilot projects to support disaster management and environmental monitoring. Proceedings, 33rd International Symposium on Remote Sensing of Environment, ISRSE 2009.

Barducci, A., Guzzi, D., Marcoionni, P., Pippi, I., 2002. Infrared detection of active fires and burnt areas: Theory and observations. Infrared Physics and Technology. http://doi.org/10.1016/S1350-4495(02)00129-9.

Barducci, A., Guzzi, D., Marcoionni, P., Pippi, I., 2004. Comparison of fire temperature retrieved from SWIR and TIR hyperspectral data. Infrared Physics and Technology. http://doi.org/10.1016/j.infrared.2004.03.001.

Barmpoutis, P., Papaioannou, P., Dimitropoulos, K., Grammalidis, N., 2020. A review on early forest fire detection systems using optical remote sensing. Sensors (Switzerland). http://doi.org/10.3390/s20226442.

Candela, L., Formaro, R., Guarini, R., Loizzo, R., Longo, F. Varacalli, G., 2016. The PRISMA mission. International Geoscience and Remote Sensing Symposium (IGARSS).

Carmona, E., Avbelj, J., Alonso, K., Bachmann, M., Cerra, D., Eckardt, A., Gerasch, B., Graham, L., Günther, B., Heiden, U., Kerr, G., Knodt, U., Krutz, D., Krawcyk, H., Makarau, A., Miller, R., Müller, R., Perkins, R., Walter, I., 2017. Data processing for the space-based desis hyperspectral sensor. International Archives of the Photogrammetry, Remote Sensing and Spatial Information Sciences - ISPRS Archives.

Cawse-Nicholson, K., Townsend, P. A., Schimel, D., et Al., 2021. NASA's surface biology and geology designated observable: A perspective on surface imaging algorithms.

Colini, L., Spinetti, C., Amici, S., Buongiorno, M. F., Caltabiano, T., Doumaz, F., Favalli, M., Giammanco, S., Isola, I., La Spina, A., Lombardo, V., Mazzarini, F., Musacchio, M., Neri, M., Salerno, G., Silvestri, M., Teggi, S., Sarli, V., Cafaro, P., Mancini, M., D’Andrea, S., Curci, G., Ananasso, C., 2014. Hyperspectral spaceborne, airborne and ground measurements campaign on Mt. Etna: Multi data acquisitions in the frame of Prisma Mission (ASI-AGI Project n. I/016/11/0). Quaderni di Geofisica.

Colini, L., Spinetti, C., Doumaz, F., Amici, S., Ananasso, C., Buongiorno, M. F., Cafaro, P., Caltabiano, T., Curci, G., D'Andrea, S., Favalli, M., Giammanco, S., Isola, I., La Spina, A., Lombardo, V., Mancini, M., Mazzarini, F., Musacchio, M., Neri, M., Puglisi, G., Salerno, G., Sarli, V., Silvestri, M., Teggi, S., 2013. 2012 hyperspectral airborne campaign on Etna: Multi data acquisition for ASI-PRISMA project. International Geoscience and Remote Sensing Symposium (IGARSS). 
Coppo, Brandani, Faraci, Sarti, Cosi, 2019. Leonardo Spaceborne Infrared Payloads for Earth Observation: SLSTRs for Copernicus Sentinel 3 and PRISMA Hyperspectral Camera for PRISMA Satellite. Proceedings. http://doi.org/10.3390/proceedings2019027001.

Coppo, P., Brandani, F., Faraci, M., Sarti, F., Dami, M., Chiarantini, L., Ponticelli, B., Giunti, L., Fossati, E., Cosi, M., 2020. Leonardo spaceborne infrared payloads for Earth observation: SLSTRs for Copernicus Sentinel 3 and PRISMA hyperspectral camera for PRISMA satellite. Applied Optics. http://doi.org/10.1364/ao.389485.

Davies, D., Ederer, G., Olsina, O., Wong, M., Cechini, M., Boller, R., 2020. NASA's Fire Information for Resource Management System (FIRMS): Near Real-Time Global Fire Monitoring Using Data from MODIS and VIIRS. NASA Technical Reports GSFC-E-DAA-TN73770.

Deb, P., Moradkhani, H., Abbaszadeh, P., Kiem, A. S., Engström, J., Keellings, D., Sharma, A., 2020. Causes of the Widespread 2019-2020 Australian Bushfire Season. Earth's Future. http://doi.org/10.1029/2020EF001671.

Dennison, P. E., Charoensiri, K., Roberts, D. A., Peterson, S. H., Green, R. O., 2006. Wildfire temperature and land cover modeling using hyperspectral data. Remote Sensing of Environment. http://doi.org/10.1016/j.rse.2005.10.007.

Dennison, P. E., Matheson, D. S., 2011. Comparison of fire temperature and fractional area modeled from SWIR, MIR, and TIR multispectral and SWIR hyperspectral airborne data. Remote Sensing of Environment. http://doi.org/10.1016/j.rse.2010.11.015.

Domenikiotis, C., Dalezios, N. R., Loukas, A., Karteris, M., 2002. Agreement assessment of NOAA/ÄVHRR NDVI with Landsat TM NDVI for mapping burned forested areas. International Journal of Remote Sensing. http://doi.org/10.1080/01431160110107707.

Domenikiotis, C., Loukas, A., Dalezios, N. R., 2003. The use of NOAA/AVHRR satellite data for monitoring and assessment of forest fires and floods. Natural Hazards and Earth System Science. http://doi.org/10.5194/nhess-3-115-2003.

Galeazzi, C., Sacchetti, A., Cisbani, A., Babini, G., 2008. The prisma program. International Geoscience and Remote Sensing Symposium (IGARSS).

Griffin, M. K., Hsu, S. M., Burke, H. h. K., Snow, J. W., 2000 Characterization and delineation of plumes, clouds and fires in hyperspectral images. International Geoscience and Remote Sensing Symposium (IGARSS).

Guanter, L., Kaufmann, H., Segl, K., et Al., 2015. The EnMAP spaceborne imaging spectroscopy mission for earth observation.

Guarini, R., Loizzo, R., Facchinetti, C., Longo, F., Ponticelli, B., Faraci, M., Dami, M., Cosi, M., Amoruso, L., De Pasquale, V., Taggio, N., Santoro, F., Colandrea, P., Miotti, E., Di Nicolantonio, W., 2018. PRISMA hyperspectral mission products. International Geoscience and Remote Sensing Symposium (IGARSS).

Hu, W., Huang, Y., Wei, L., Zhang, F., Li, H., 2015. Deep convolutional neural networks for hyperspectral image classification. Journal of Sensors. http://doi.org/10.1155/2015/258619.

Hua, L., Shao, G., 2017. The progress of operational forest fire monitoring with infrared remote sensing. Journal of Forestry Research. http://doi.org/10.1007/s11676-016-0361-8.

Kaufman, Y. J., Justice, C., Flynn, L., Kendall, J., Prins, E. Ward, D. E., Menzel, P., Setzer, A., 1998. Monitoring Global Fires from EOS-MODIS. Journal of Geophysical Research.
Key, C. H., Benson, N. C., 2006. Landscape assessment (LA). In: Lutes, Duncan C.: Keane, Robert E.; Caratti, John F; Key, Carl H.; Benson, Nathan C.; Sutherland, Steve; Gangi, Larry J. 2006. FIREMON: Fire effects monitoring and inventory system. Gen. Tech. Rep. RMRS-GTR-164-CD. Fort Collins, CO: US Department of Agriculture, Forest Service, Rocky Mountain Research Station. p. LA-1-55, 164.

Kumar, S. V., Holmes, T., Andela, N., Dharssi, I., Vinodkumar, Hain, C., Peters-Lidard, C., Mahanama, S. P., Arsenault, K. R., Nie, W., Getirana, A., 2021. The 2019-2020 Australian Drought and Bushfires Altered the Partitioning of Hydrological Fluxes.

Loizzo, R., Ananasso, C., Guarini, R., Lopinto, E., Candela, L., Pisani, A. R., 2016. The prisma hyperspectral mission. European Space Agency, (Special Publication) ESA SP.

Loizzo, R., Daraio, M., Guarini, R., Longo, F., Lorusso, R., DIni, L., Lopinto, E., 2019. Prisma Mission Status and Perspective. International Geoscience and Remote Sensing Symposium (IGARSS).

Loizzo, R., Guarini, R., Longo, F., Scopa, T., Formaro, R., Facchinetti, C., Varacalli, G., 2018. Prisma: The Italian hyperspectral mission. International Geoscience and Remote Sensing Symposium (IGARSS).

Lopinto, E., Cerone, M., Tempesta, P., Sacchetto, M., Michetti, A., Cenci, A., Signorile, S., 2012. Streamlined approach to the operations of PRISMA. SpaceOps 2012 Conference.

Matheson, D. S., Dennison, P. E., 2012. Evaluating the effects of spatial resolution on hyperspectral fire detection and temperature retrieval. Remote Sensing of Environment. http://doi.org/10.1016/j.rse.2012.06.026.

Nieke, J., Rast, M., 2018. Towards the copernicus hyperspectral imaging mission for the environment (CHIME). International Geoscience and Remote Sensing Symposium (IGARSS).

Piscini, A., Amici, S., 2015. Fire detection from hyperspectral data using neural network approach. Remote Sensing for Agriculture, Ecosystems, and Hydrology XVII.

Pitman, A. J., Narisma, G. T., McAneney, J., 2007. The impact of climate change on the risk of forest and grassland fires in Australia. Climatic Change. http://doi.org/10.1007/s10584007-9243-6.

Veraverbeke, S., Dennison, P., Gitas, I., Hulley, G., Kalashnikova, O., Katagis, T., Kuai, L., Meng, R., Roberts, D., Stavros, N., 2018. Hyperspectral remote sensing of fire: State-ofthe-art and future perspectives.

Vodacek, A., Kremens, R. L., Fordham, A. J., Vangorden, S. C., Luisi, D., Schott, J. R., Latham, D. J., 2002. Remote optical detection of biomass burning using a potassium emission signature. International Journal of Remote Sensing. http://doi.org/10.1080/01431160110109633.

Waigl, C. F., Prakash, A., Stuefer, M., Verbyla, D., Dennison, P., 2019. Fire detection and temperature retrieval using EO-1 Hyperion data over selected Alaskan boreal forest fires. International Journal of Applied Earth Observation and Geoinformation. http://doi.org/10.1016/j.jag.2019.03.004

Weber, D., Moskwa, E., Robinson, G. M., Bardsley, D. K., Arnold, J., Davenport, M. A., 2019. Are we ready for bushfire? Perceptions of residents, landowners and fire authorities on Lower Eyre Peninsula, South Australia. Geoforum. http://doi.org/10.1016/j.geoforum.2019.10.006. 